\title{
A RARE CASE OF BILATERAL POSTERIOR TEMPOROMANDIBULAR JOINT DISLOCATION
}

\author{
Vishwas K. V11, K. Srirangaprasad², Sowmya $S^{3}$
}

${ }^{1}$ Assistant Professor, Department of Otorhinolaryngology, Rajarajeswari Medical College and Hospital, Bangalore.

2 Professor, Department of Otorhinolaryngology, Rajarajeswari Medical College and Hospital, Bangalore.

${ }_{3}^{3}$ Postgraduate Resident, Department of Otorhinolaryngology, Rajarajeswari Medical College and Hospital, Bangalore.

\section{ABSTRACT}

\section{BACKGROUND}

Mandibular dislocation is not uncommon. It is the dislocation of the condyle from the glenoid fossa of the temporal bone, ultimately restricting movements. It is seen secondary to lax intra-articular ligaments or periarticular or as a result of injury. In the operative setting, applying a mouth gag for tonsillectomy or oral procedures is known to dislocate the temporomandibular joint, which can be relocated after removal of the mouth gag. Most of these are managed and reduced in emergency department. Manual reduction can be done for acute dislocations but the chronic cases are difficult to manage. ${ }^{1}$ Unilateral dislocation is common but bilateral condition is rare. Herein we report a case of posterior dislocation of mandibular condyle, which was bilateral and longstanding before the patient presented to us.

\section{KEYWORDS}

Temporomandibular Joint (TMJ), Subluxation, Tympanic Ring Fracture.

HOW TO CITE THIS ARTICLE: Vishwas KV, Srirangaprasad K, Sowmya S. A rare case of bilateral posterior temporomandibular joint dislocation. J. Evolution Med. Dent. Sci. 2017;6(29):2400-2402, DOI: 10.14260/Jemds/2017/517

\section{BACKGROUND}

The mandible interfaces with the skull base via the temporomandibular joint and is held in position by the muscles of mastication and intra-articular and periarticular ligaments. Dislocation of the mandible can occur anteriorly or posteriorly or laterally or superiorly. Anterior dislocations are the most common and result in displacement of the condyle anterior to the articular eminence into the infratemporal fossa. Posterior dislocations occur as a result of direct blow to chin and condyle pushed posteriorly towards the mastoid causing damage to the external auditory canal. Dislocation or subluxation of the condyle unilaterally is common but bilateral cases are rare and need proper assessment and treatment. Manual reduction may be difficult to reduce after certain period because of fibrous tissue within glenoid fossa. ${ }^{2,3}$

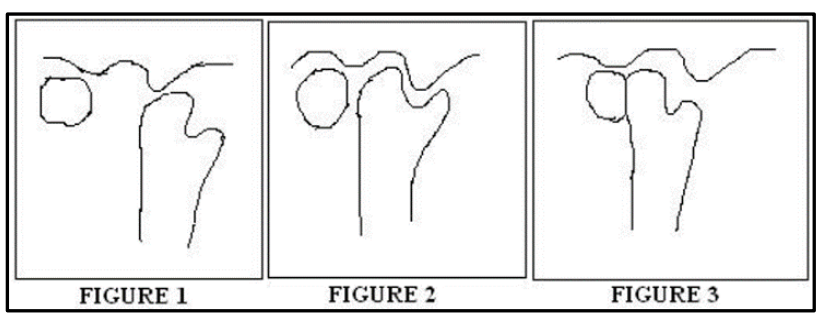

Figure 1. Anterior Dislocation of the Condyle Figure 2. Normal Temporomandibular Joint Anatomy Figure 3. Posterior Dislocation of the Condyle

Financial or Other, Competing Interest: None.

Submission 02-03-2017, Peer Review 25-03-2017,

Acceptance 01-04-2017, Published 10-04-2017.

Corresponding Author:

Dr. Sowmya $S$,

D/o. Shivashankar Reddy,

\#36, Guddahatti, Attibele,

Anekal,

Bangalore-562107.

E-mail: sowmyareddy1189@gmail.com

DOI: $10.14260 /$ jemds $/ 2017 / 517$

\section{(c)}

\section{CASE REPORT}

A 70-year-old diabetic patient presented 20 days after a selffall on the chin following which he had complaints of difficulty in opening mouth and inability to chew the food. It was associated with pain in the temporomandibular joint region. He also complained of hearing loss with severe bilateral ear pain with occasional ear bleeding.

On examination, the mouth opening was restricted with grade 3 malocclusion. Tenderness was elicited in the temporomandibular joint region.

Ear examination showed bilateral occluded canal with minimal blood clots. Tympanic membrane was not visualised. The locoregional causes of trismus was ruled out and a probable temporomandibular dislocation was suspected. In order to rule out a condylar neck or condylar base fracture which accompanies a dislocation of condyle, a computed tomography was done.

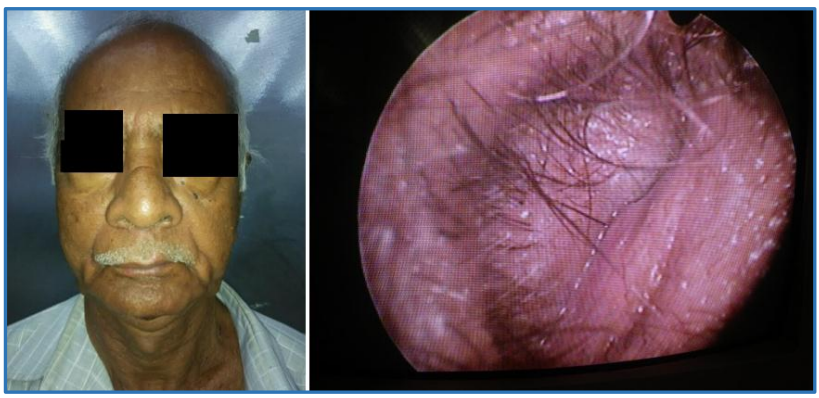

Figure 4. Preoperative Photo and Endoscopic View of the Occluded External Auditory Canal

Patient was evaluated for the fractures with Computerised Tomography of facial skeleton which showed bilateral condylar dislocation posteriorly, causing occlusion of bilateral external auditory canals, with no evidence of any condylar fractures. Dislocation of bilateral condyles posteriorly, occluding the external auditory canal, caused a fracture of the anterior plate of the tympanic bone. 


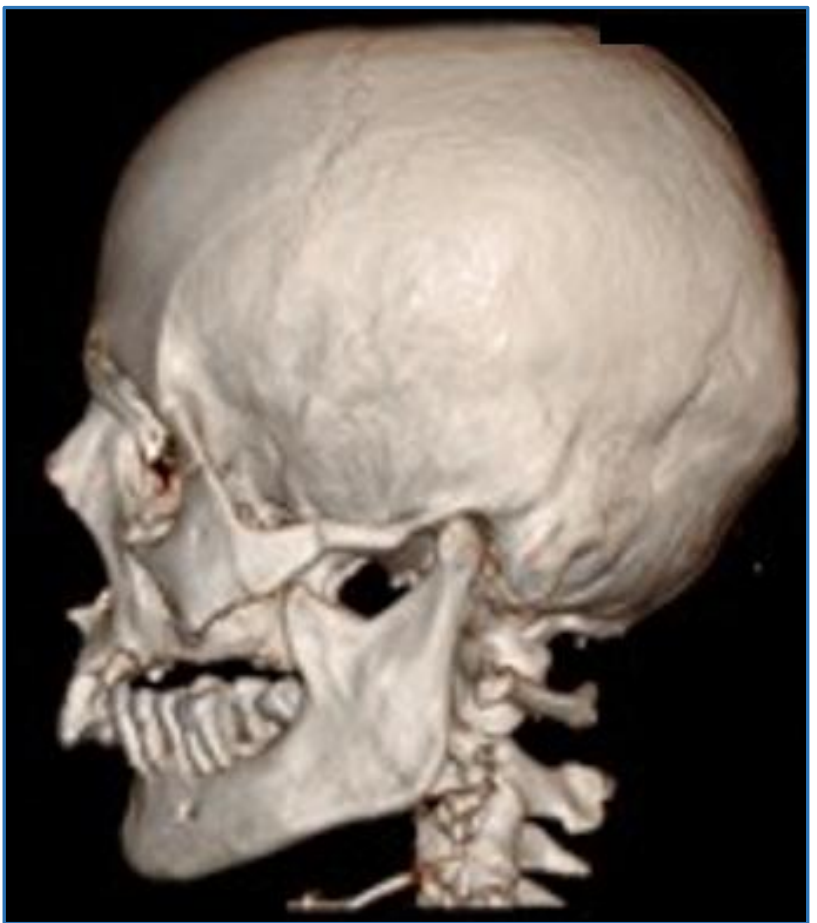

Figure 5. 3D Reconstruction of the Facial Skeleton Showing Posterior Dislocation of the Condyle on the Left Side
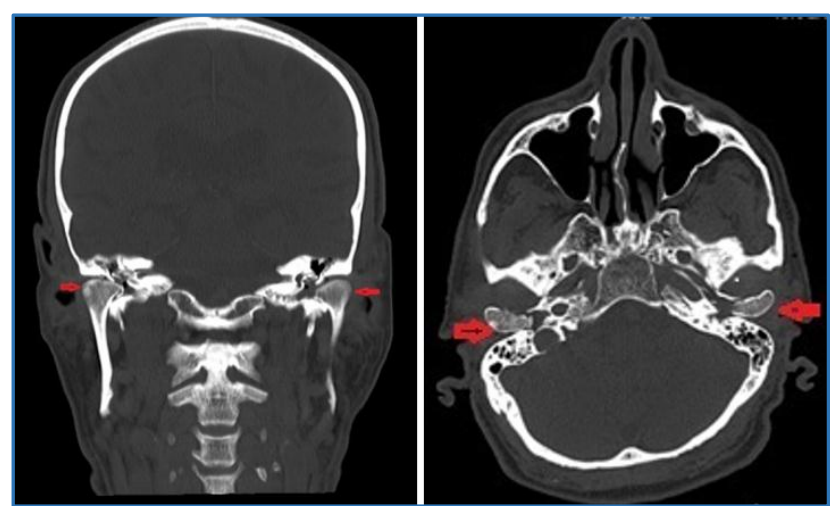

Figure 6. Coronal and Axial CT-Scan

Hence, the patient was planned for the surgery after preoperative workup.

Procedure: Under general anaesthesia with orotracheal intubation, in supine position, manual reduction of the condyles were tried with muscle relaxation, but was unsuccessful.

Incision measuring around $2.5 \mathrm{~cm}$ was given at the angle of mandible and the incision deepened in layers to identify masseter muscle, which was partially released from the ramus of the mandible. The same procedure was repeated on the opposite side. The angle of mandible was held with the Kocher's forceps and reduction of the dislocation was done in a downward and forward direction. Relocation of the joint was confirmed with a palpatory click and return of occlusion with the maxillary and mandibular dentition in opposition.

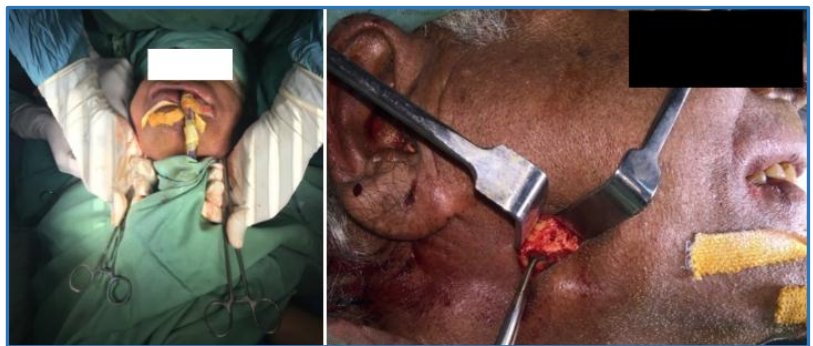

Figure 7. Intraoperative Picture Showing the Process of Reduction

External auditory canal was visualised with a microscope and the canal occlusion released as the reduction was done. A stent prepared from endotracheal tube and the Merocel pack with antibiotic ointment was placed in the canals.

The incision closed in layers after achieving complete haemostasis and dressing applied. During extubation from the deep anaesthesia, the condylar head was held in position to avoid any more slippages by the anaesthesiologist. Patient made an uneventful recovery from the anaesthesia.

Postoperatively, patient was advised spoon feeds and oral antibiotics and analgesics.

Patient's mouth opening was adequate and occlusion was good postoperatively and hearing improved. The patient had normal occlusion postoperatively with no pain. He was allowed to resume normal diet by soft chewing after the surgical reduction, in order to break any further fibrosis and early mobilisation. However, he was allowed hard chews only after 2 weeks.

The patient's hearing drastically improved and the conductive loss minimised and his diabetic status improved secondary to resumption of normal diet.

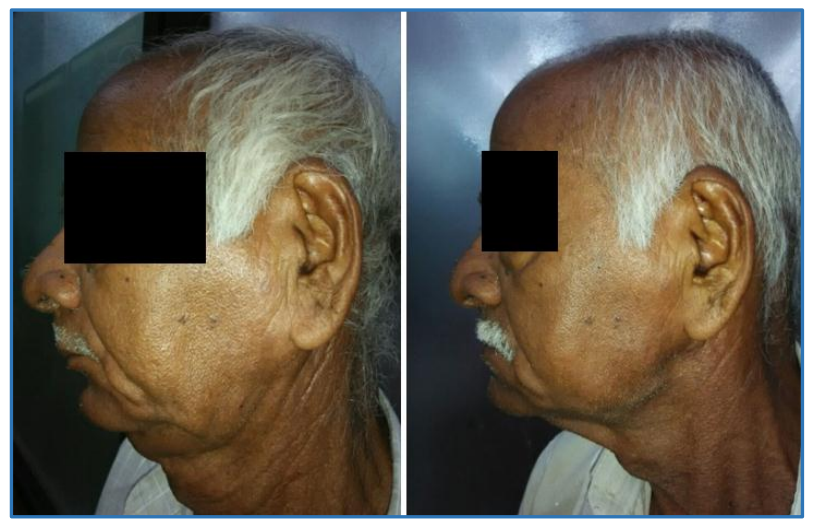

Figure 8. Preoperative Picture and Postoperative Picture Showing Chin Position

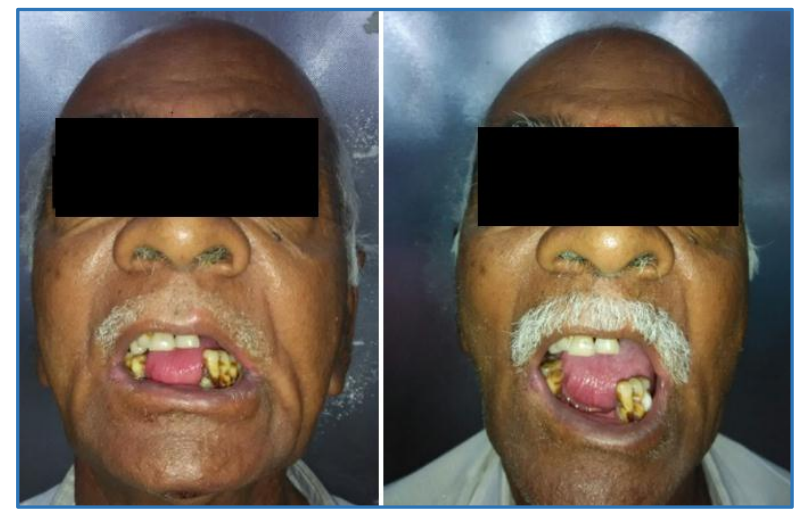

Figure 9. Mouth Opening Preoperative and Postoperative Picture 


\section{DISCUSSION}

Patients with bilateral dislocation of the condyles are rare and proper management is required for a good outcome. Hitherto this patient had a posterior dislocation of condyle, which is even more rarer. The diabetes and the longstanding duration complicated the presentation and outcome.

Temporomandibular joint is located anterior to external auditory canal and has two articulating components: mandibular condyle and glenoid fossa which is limited by petrotympanic fissure. The posterior part of glenoid fossa is formed by anterior tympanic plate which is thin and weak. There is herniation of Temporomandibular joint into External auditory canal commonly because of trauma. This can lead to fracture of the condyle, posterior dislocation, into Middle cranial fossa.

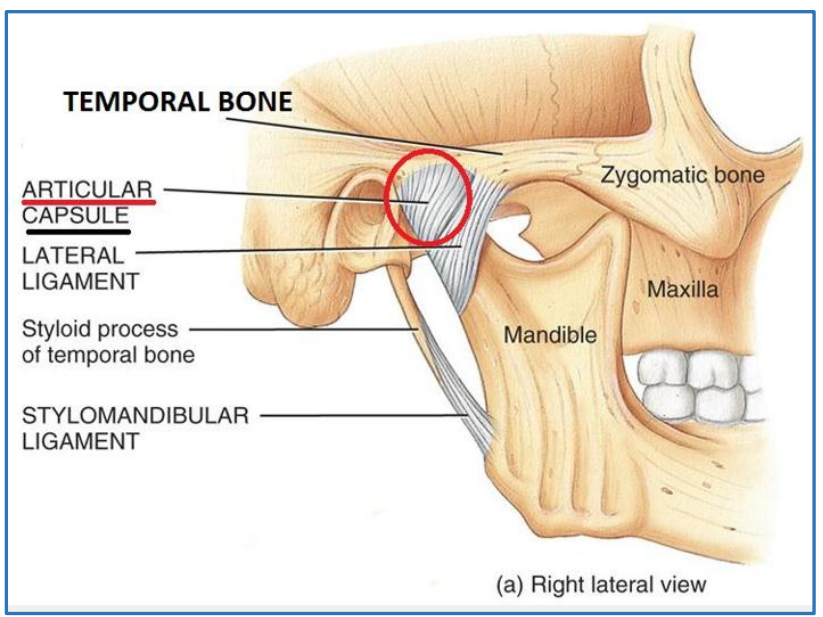

Figure 10. Normal Anatomy of the Temporomandibular Joint

Late presentation to the hospital may be because of the ignorance. Cases of longstanding condyle posterior dislocation causes muscle spasm and can lead to fibrosis.

Typically, condyle dislocations are managed conservatively or surgically. In most of the acute conditions, manual reduction with or without anaesthesia is done. $4,5,6$

Chronic bilateral cases are more commonly seen in elderly and are more difficult to manage manually. ${ }^{7}$

In our case, manual reduction of the dislocation was attempted in emergency department, but could not succeed. Then we planned for manual reduction under muscle relaxation. However, due to the chronicity of the condition, fibrosis had ensued leading to failure in reduction. Our next plan of management was to surgically reduce under full general anaesthesia. The classic reduction technique with physician's gloved thumbs on the patient's inferior molars was difficult. We planned an incision at the angle of the mandible to release part of the masseter from the ramus of the mandible. We realised that inferior and anterior relocation was much easier by holding at the angle of mandible and retracting forward. If this approach had failed, we would have resorted to exposing the temporomandibular joint and adhesiolysis to release the condyle from its new place of resting. There have been some reports of condylectomy as a last measure. We succeeded in reducing the TM joint with minimal incision at the angle of the mandible.

\section{CONCLUSION}

There are many methods of condylar management, but minimal data is available on dislocation of the condyle. Bilateral and posterior dislocation is a rare case entity and optimal management is important for better outcome. In our case, the patient had adequate mouth opening and good occlusion postoperatively.

\section{REFERENCES}

[1] Navas RMA, Mendoza MGM. Inverse temporomandibular joint dislocation. Int j Oral Maxillofac Surg 2011;40(8):877-9.

[2] Hammersley N. Chronic bilateral dislocation of temporomandibular joint. Br J oral Maxillofac Surg 1986;24(5):365-75.

[3] Litter BO. The role of local anaesthesia in the reduction of long-standing dislocation of the temporomandibular joint. Br J Oral Maxillofac Surg 1980;18(1):81-5.

[4] Adekeye EO, Shamia RI, Cove P. Inverted L-shaped ramus osteotomy for prolonged bilateral dislocation of the temporomandibular joint. Oral surg oral med oral patho 1976;41(5):568-77.

[5] Caminiti MF, Weinberg S. Chronic mandibular dislocation: the role of non-surgical and surgical treatment. J Can Dent Assoc 1998;64(7):484-91.

[6] Gray RJ, Davics SJ. Emergence treatment of acute temporomandibular disorders: part II. Dent update 1997;24(5):186-9.

[7] Kurita K, Mukaida Y, Ogi N, et al. Closed reduction of chronic bilateral temporomandibular joint dislocation. A case report. Int j Oral Maxillofac Surg 1996; 25(6):422-3. 